NATALia BATsun

Irkutsk State Technical University, Russia

\title{
Quality of Life and Market
}

Market by itself cannot deduce economy from crisis. For this purpose it is necessary to lay the foundation for development of production and quality of life of the population on the basis of a deep analysis of the real economic situation.

For the crisis, some negative processes occurring in all spheres of public system are characteristic, that is: social stratification, the decrease of economy and environmental deterioration.

Quality of life is a complex social and economic category. Only having comprehensively estimated the standard of living, as well as social and economic aspects of development of a society for some period of time, it is possible to judge the quality of life of the population.

Market system is imperfect from the point of view of the improvement of the quality of life, the basic components of which are: population health, education, quality of human resources, environmental safety, etc. The market is not focused on manufacturing socially important goods, it has no perfect economic mechanism for securing environmental safety.

If manufacturing of some products leads to environmental contamination it brings, as a rule, additional expenses.

Life quality management is then, first of all, investing into forming the qualitative population and healthy manpower. The faults of existing approaches to forming the programs of quality of life are as follows:

- lack of unequivocal definition of the very category «quality of life» and indicators characterizing it, as well as the factors influencing dynamics of these indicators;

- lack of the unified methodological basis for estimating an integrated indicator of quality of life for efficient control of economic and social situation of the regions;

- low methodical level of analyzing, planning and forecasting social and economic processes which in reality takes place without taking into account any factors of maintaining quality of life;

- lack of systematic approach in working out the programs' purposes, threats and realization methods;

- lack of the links between the programs of improvement of the quality of life and regional investments' programs.

Interaction between the state institutions and business can be effective if this interaction is directed at overall aims of achievement, and quality could be such a purpose. 
The search of new ways of economic development has led to recognition that only quality of life can express to the greatest degree the society purposes, as competitiveness of the countries in the world market is now evaluated according to quality factors.

After introduction of standards of series ISO 9000-2000 the key concept, «quality system», was replaced with the concept of «quality management system», the main principles of which are:

- orientation at the consumer;

- using process approach;

- using systems approach;

- permanent improvement of activity of the organization.

Nowadays problems of estimating human capital and its role in increasing the volume of national wealth are becoming increasingly important though there are no unified principles of calculating this complex indicator. A growing economy having positive rates of economic growth is characterized by a gain of annual real product which gives the chance to more comprehensively and more effectively satisfy constantly increasing requirements of the society. The increase in real earnings expands the circle of possibilities for people in realization of their requirements. At the same time economic growth allows the society to carry out new social and economic programs without the decrease in existing consumption level, reduction of volumes of investments and manufacturing of public goods.

More and more popular is becoming the concept of quality of life of the population, quality of activities, as a guarantee of sustainable economic development, rather than evaluating quality of goods and services.

Modern researchers of quality of life find it necessary to consider this category as a systemic integrity which is expressed through a complex structure of interrelations of its components: quality of environment, quality of health of the population, quality of education, quality of culture.

Quality is a complex concept, not fully clear by now. Leaning at the experience of industrially developed countries, it is possible to tell that quality is a political, economic and moral category. Quality of a product, of work, of service, is expressed through the profit of an independent economic unit and, hence, of those who create this quality. Quality of public health services and of environment is people's health. Quality of education is high cumulative intellect of labor force. Altogether, it is high level of mental comfort of people, prestige of the nation and the state, that is quality of life.

Among obvious defects, preventing to determine the problems of quality of life in Russian Federation, there are insufficient normative and legal spaces in the sphere of evaluating the quality of life, poor estimation of the development purposes and directions, poor economic support. For solving each task, it is necessary to develop a socio-economic program with a corresponding financial maintenance, as well as the criteria of estimating advancement of these programs to the planned purpose - maintenance of the quality of life.

The categories «way of life», «style of life», «standard of living» generalize certain qualitative and quantitative aspects of people's life. An integrated, complete expression of qualitative aspects of life is concentrated in the category «quality of life».

On the basis of the category «style of life», it is possible to consider the types of behavior of social groups and individuals, of their manners, features, tastes, propensities. For example, a characteristic feature for a number of social groups is orientation on a high quality of goods and services. The category «standard of living» provides one more major parameter of any 
social system. The standard of living characterizes the quantitative aspect of life comparable with qualitative degree of satisfying material and cultural requirements of people. On the basis of this category the estimation of well-being of the society and its social groups is made.

The standard of living of a person and of the population as a whole depends on the degree of satisfying one's requirements and is defined by one's resources and possibilities. The backbone basis of the notion of standard of living are various human needs arising and realized in the sphere of consumption. The category «quality of life» is an integrated qualitative characteristic of life of people which specifies not only activity and life-provision, but also viability of the society as an integral social organism, its social qualities.

For a human being, not only a certain standard of well-being is important, but also the state of environment, state of one's health, availability of free time, freedom of choice of the activities.

To provide the desired quality in various areas of life in Russia, it is necessary to combine skillfully and competently the use of mechanisms of state and municipal management, to target investments, to perfect the forms of organization of production, standardization, certification, legislation, etc.

Some economists offer the concept where quality of life should be estimated from the position of its interrelation with the quality of the population, taking into account results of the analysis of existing indicators of quality of life $(\mathrm{QL})$, ideas on characteristics of the quality of the population (QP) and the data of psychological testing of various social groups of Russian society, as well as the quality of living conditions (QC). The category «quality of the population» is a resource and guarantor of stable development, the basis of national economic safety of the state. The quality of the population is inseparable from activity of people, from quality of manpower (QM), from their environment, it has a historical character and is defined by corresponding way of production.

Almost all characteristics of the activity are interconnected with direct connections and feedbacks and their set is a complex, purpose-orientated system which organically connects the quality of the population and the quality of life. As a result, the quality of the population through the sphere of requirements causes substantial basis of indicators of quality of life.

$$
\begin{aligned}
& \mathrm{QL}=\mathrm{f}(\mathrm{QP}, \mathrm{QM}) \\
& \mathrm{QM}=\mathrm{f}(\mathrm{QL}, \mathrm{QP}) .
\end{aligned}
$$

Criterial values of indicators should be differentiated according to the classes of requirements. Requirements are inherent to any person and are one's distinctive feature. However, the concrete structure of requirements, their quantitative and qualitative definiteness are the product of socio-historical development.

Recently, the demand for environmentally pure production has been increasing, and if some new requirements occur, there should be a new offer satisfying the new consumer's formats. The market of environmentally pure production in Russia has been yet limited in comparison with other countries.

Environmental business is today one of the most attractive capital investment spheres. It is supposed that the companies, which have realized and introduced the strategy of using environmental component of business earlier than others, will obtain new possibilities and real advantages. 
Solving environmental problems can often bring to emergence of new possibilities and to receiving new benefits by the enterprises (shown in table 1, created by the author).

Tab. 1. Organizational-economic benefits from implementation of environmental management

\begin{tabular}{|l|l|}
\hline \multicolumn{1}{|c|}{ Effects } & \multicolumn{1}{c|}{ Results } \\
\hline $\begin{array}{l}\text { Development of the system of strategic } \\
\text { and tactical management }\end{array}$ & $\begin{array}{l}\text { Stability and flexibility increase } \\
\text { Controllability increase }\end{array}$ \\
\hline $\begin{array}{l}\text { Favorable image and good relations with } \\
\text { consumers, partners, investors, state structures } \\
\text { and the public }\end{array}$ & $\begin{array}{l}\text { Mutually advantageous and long-term } \\
\text { cooperation } \\
\text { Growth of the market capitalization } \\
\text { Increase in investment attractiveness }\end{array}$ \\
\hline $\begin{array}{l}\text { Competitiveness increase in the internal and } \\
\text { external markets, decrease in risks }\end{array}$ & $\begin{array}{l}\text { Increase of competitive advantages } \\
\text { Obtaining investment offers }\end{array}$ \\
\hline $\begin{array}{l}\text { Reduction of industrial, operational and other } \\
\text { expenses }\end{array}$ & $\begin{array}{l}\text { Decrease in the cost price of production } \\
\text { Profit increase }\end{array}$ \\
\hline $\begin{array}{l}\text { Additional sources of income at the expense } \\
\text { of processing of waste }\end{array}$ & $\begin{array}{l}\text { Profit increase } \\
\text { Decrease in costs } \\
\text { Additional possibilities for development } \\
\text { of business activity }\end{array}$ \\
\hline
\end{tabular}

The increase of competitive advantages emerges, as the companies investing into non-polluting technologies earlier than others, have a chance to become leaders, first of all in the home market; the competitors not capable to sustain high ecological standards have to leave the market.

The problem of forming an environmentally responsible consumer in Russia has been still unsolved.

The functions of the state in developing environmental business and improving the conditions of its activity are as follows:

- to stimulate with special financial and credit levers production of environmental goods and developing the sphere of environmental services;

- to stimulate effective demand for environmental production and services first of all with a policy of the state acquisitions;

- to provide the facilitated access for the enterprises making environmental production, to the services given by the governmental structures;

- to participate directly in marketing and demonstration of samples of environmental technologies;

- to promote greening of banks;

- to publish periodic information materials containing constantly updated information on possibilities for projects, development of the nature protection legislation;

- to create additional trust funds for investment of the environmental industry which would promote maintenance of the corresponding enterprises with the starting capital and their 
financing at early stages of development, or to allocate for this purpose a part of already existing governmental funds, for example, funds of development of the enterprises, for financing the suppliers of the ecological goods.

Environmental brands are to some extent the second wave in consumer society evolution. Overpaying for a brand, a person gets some quite clear privileges - for example, an advantage (or, at least, absence of harm) for health. And, as a result, the sense of correct way of living, which is, of course, the most important bonus to be paid for.

Such an economic concept will help Russia to become a real participant in modern world economic communications and to join the processes of globalization, while a serious obstacle can be the gap between the quality of Russian goods and international environmental standards.

\section{Quality of Life and Market}

The market system is imperfect from the point of view of improvement of quality of life, the basic components of which are: population health, education, quality of human resources, environmental safety, etc. The market is not focused on manufacturing socially important goods, it has no perfect economic mechanism for securing environmental safety.

The search of new ways of economic development has led to recognition that only quality of life can express to the greatest degree the society purposes, as well as the competitiveness of the countries in the world market.

Among obvious defects, preventing to determine of problems of the quality of life in Russian Federation, there are: insufficient normative and legal space in the sphere of evaluating quality of life, poor estimation of the development purposes and directions, and poor economic support. For solving each task, it is necessary to develop a socio-economic program with a corresponding financial maintenance, as well as the criteria of estimating the advancement of these programs to the planned purpose - which is the maintenance of the quality of life.

doc. Natalia Batsun, Docent

Irkutsk State Technical University, Russia

e-mail: nbatsun@mail.ru 